Editorial: Open Access

\title{
Embracing Reward Deficiency Syndrome (RDS) Solution System: A Genomic Thrust
}

\author{
Kenneth Blum ${ }^{1-6 *}$, Marcelo Febo' ${ }^{1}$, Zsolt Demotrovics ${ }^{7}$ and Rajendra D. Badgaiyan ${ }^{8}$ \\ ${ }^{1}$ Department of Psychiatry \& McKnight Brain Institute, University of Florida, College of Medicine, USA \\ ${ }^{2}$ Department of Psychiatry, Human Integrated Services Unit, University of Vermont Center for Clinical \& Translational \\ Science, University of Vermont College of Medicine, Burlington, USA
}

${ }^{3}$ Department of Addiction Research \& Therapy, Malibu Beach Recovery Center, Malibu Beach, USA

${ }^{4}$ Dominion Diagnostics, LLC. North Kingstown, USA

${ }^{5}$ Department of Nutrigenomics, Victory Nutrition International, Austin, USA

${ }^{6}$ Department of Personalized Medicine, RDSolutions, Inc., Del Mar, USA

${ }^{7}$ Eotvos Lorand University, Institute of Psychology, Department of Clinical Psychology and Addiction, Hungary

${ }^{8}$ Department of Psychiatry, University of Minnesota, School of Medicine, USA

*Corresponding author: Kenneth Blum, Department of Psychiatry \& McKnight Brain Institute, University of Florida, College of Medicine, USA, E-mail: drd2gene@gmail.com

\section{WC-726}

The mysteries and underlying causes of addictive disorders have spawned a number of important questions which still plague researchers and treatment professionals alike. What populations are susceptible to addictive disorders based upon genetic predisposition? Why are they more susceptible than others? What considerations or adjustments must be made to care plans of certain individuals to maximize their opportunity for recovery?

The Brain Reward Cascade (BRC) first proposed by Blum \& Kozlowski in 1989 [1] is an interaction of neurotransmitters and their respective genes to control the amount of dopamine released within the brain. Any variations within this pathway, whether genetic or environmental (epigenetic) [2], may result in addictive behaviors or RDS, which was coined to define addictive behaviors and their genetic components [3].

While there are many studies claiming a genetic association with RDS behavior, not all are scientifically accurate. Another issue in RDS treatment involves 1) compliance or adherence to prescribed treatment medications during treatment; 2) remaining abstinent from all drugs of abuse during treatment. While there is a plethora of very positive experiments involving thousands of studies for many candidate gene associations with all RDS behaviors, there are also negative results [4]. Currently, a number of companies have entered the genetic testing arena in the addiction and pain industrial space claiming "personalized care" [5]. However, we believe these companies have not done their homework in a scientific manner.
These issues include exaggerated claims such as stating that their genetic test is $74 \%$ predictive based on only one gene (DRD2) not their panel of genes claimed to be tested [6]; claims suggesting that patient's results are compared to population controls [7]; selection of genes that may be involved in risky behavior but they do not utilize the correct variant in their tests or use very rare variants that do not truly prove addiction risk [8]; never performed research to show whether their "genetic test" significantly predicts anything let alone addiction risk or any associated behaviors [5].

In an attempt to overcome these pitfalls our laboratory has successfully developed the first Genetic Addiction Risk Score $\left(\text { GARS }_{\mathrm{Dx}}\right)^{\prime \prime}$ in conjunction with Dominion Diagnostics, LLC. Certainly genetic risk stratification for RDS prior to or upon entry into chemical dependency programs can provide information central to the implementation of appropriate treatment and relapse prevention [9]. When we selected 10 genes with appropriate variants, a statistically significant association between the ASI- Media Version -alcohol and drug severity scores and GARS ${ }_{D x}$ was found While a complete detail of this research is to be submitted elsewhere, in 273 patients attending seven diverse treatment centers the GARS predicted both high alcohol and drug severity as measured by ASIMedia version [10].

Drug abuse and adherence to treatment medications, was investigated in a large sample of patients from chemical dependency programs, using Comprehensive Analysis of Reported Drugs (CARD) data. This post-hoc retrospective observational study of data collected in 2010 - 2011 from 10,570 patients reduced to a total


International Library
Citation: Blum K, Febo M, Demotrovics Z, Badgaiyan RD (2015) Embracing Reward Deficiency Syndrome (RDS) Solution System: A Genomic Thrust. Int Arch Addict Res Med 1:001e

Received: February 16, 2015: Accepted: February 18, 2015: Published: February 21, 2015

Copyright: () 2015 Blum K. This is an open-access article distributed under the terms of the Creative Commons Attribution License, which permits unrestricted use, distribution, and reproduction in any medium, provided the original author and source are credited. 
of 2,919 patients with at least one prescribed treatment medication has been published in PLOSONE. Test results from the first and last analyzed urine samples (5,838 specimens) were used as well as a subset longitudinal analysis [11].

One unpublished important finding related to buprenorphine/ naloxone in opiate treatment programs related to both compliance and abstinence issues. Buprenorphine/naloxone was $87.4 \%$ [ $\mathrm{n}=1135]$ compliant. In contrast, abstinence during treatment with Buprenorphine/naloxone was 52.7\% [ $\mathrm{n}=609]$. In a subset of $17.5 \%(n=510)$ a longitudinal analysis of all urine samples revealed significant improvement in compliance and abstinence over the course of treatment. There was a significant reduction of opiate abuse in this population. A promising finding that may have impact on the current FDA 100 patient restriction [12].

Based on this seminal research and unlike other existing genetic tests we are poised to launch the first proven and validated genetic addiction risk score that will have important clinical benefits including medical monitoring for better clinical outcome and pharmaceutical response and assessment of RDS risk [13]. Clinically, the future is here and the treatment of chronic addiction and pain depends on scientifically sound appropriate early genetic risk diagnosis and drug urine screening leading to real personalized care of the patient. Finally, we question the wisdom of utilizing FDA approved Medical Assisted Treatment (MAT) in the long term based on blocking dopaminergic function, instead of dopamine agonistic therapy (DAP) $[14,15]$ as suggested by recent work by many [16-20] involving resting state functional connectivity, for the treatment of all associated RDS behaviors both substance related and non-substance related [21].

\section{Aknowledgement}

K. Blum is $100 \%$ owner of Synaptamine Inc. holding a number of nutrigenomic patents worldwide including genetic testing of RDS. K Blum is a paid consultant of Malibu Beach Recovery Center owned by Rivermend Health. He is has stock in Victory Nutrition International ,LLC and RDSolutions, inc. The authors have no other relevant affiliations or financial involvement with any organization or entity with a financial interest in or financial conflict with the subject matter or materials discussed in the manuscript part from those disclosed. Kenneth Blum is the recipient of a grant from The Life Extension Foundation, Ft. Lauderdale, FL, USA to Path Foundation, NY, USA. Dr. Badgaiyan is supported by the National Institutes of Health grants 1R01NS073884 and 1R21MH073624, and VA Merit Review Awards CX000479 and CX000780. Marcelo Febo is the recipient of R01DA019946.

\section{References}

1. Blum K, Kozlowski GP (1990) Ethanol and neuromodulator interactions: cascade model of reward. In: Ollat $\mathrm{H}$, Parvez S, Parvez $\mathrm{H}$ (eds). Alcohol and Behavior. Utrecht, Netherlands: VSP Press.131-149.

2. Brami-Cherrier K, Anzalone A, Ramos M, Forne I, Macciardi F, et al. (2014) Epigenetic reprogramming of cortical neurons through alteration of dopaminergic circuits. Mol Psychiatry 19: 1193-200.

3. Blum K, Febo M, McLaughlin T, Cronjé FJ, Han D, et al. (2014) Hatching the behavioral addiction egg: Reward Deficiency Solution System (RDSS) ${ }^{\mathrm{TM}}$ as a function of dopaminergic neurogenetics and brain functional connectivity linking all addictions under a common rubric. J Behav Addict 3:149-156.

4. Gorwood P, Le Strat Y, Ramoz N, Dubertret C, Moalic JM, et al. (2012) Genetics of dopamine receptors and drug addiction. Hum Genet 131: 803822

5. Trescot AM, Faynboym S (2014) A review of the role of genetic testing in pain medicine. Pain Physician 17: 425-445

6. Blum K, Sheridan PJ, Wood RC, Braverman ER, Chen TJ, et al. (1996) The D2 dopamine receptor gene as a determinant of reward deficiency syndrome. J R Soc Med 89: 396-400.

7. Chen TJ, Blum K, Mathews D, Fisher L, Schnautz N, (2005) Are dopaminergic genes involved in a predisposition to pathological aggression? Hypothesizing the importance of "super normal controls" in psychiatricgenetic research of complex behavioral disorders. Med Hypotheses 65: 703-707.

8. Oertel B, Lötsch J (2008) Genetic mutations that prevent pain: implications for future pain medication. Pharmacogenomics 9: 179-194.

9. Blum K, Oscar-Berman M, Jacobs W, McLaughlin T, Gold MS (2014) Buprenorphine Response as a Function of Neurogenetic Polymorphic Antecedents: Can Dopamine Genes Affect Clinical Outcomes in Reward Deficiency Syndrome (RDS)? J Addict Res Ther 5.

10. Black RA, Trudeau KJ, Cassidy TA, Budman SH, Butler SF (2013)
Associations between public health indicators and injecting prescription opioids by prescription opioid abusers in substance abuse treatment. J Opioid Manag 9: 5-17.

11. Blum K, Han D, Femino J, Smith DE, Saunders S, et al. (2014) Systematic evaluation of "compliance" to prescribed treatment medications and "abstinence" from psychoactive drug abuse in chemical dependence programs: data from the comprehensive analysis of reported drugs. PLoS One 9: 104275 .

12. Wakhlu S (2009) Buprenorphine: a review. J Opioid Manag 5: 59-64

13. Blum K, Oscar-Berman M, Demetrovics Z, Barh D, Gold MS (2014) Genetic Addiction Risk Score (GARS): molecular neurogenetic evidence for predisposition to Reward Deficiency Syndrome (RDS). Mol Neurobiol 50: 765-796.

14. Volkow ND, Frieden TR, Hyde PS, Cha SS (2014) Medication-assisted therapies--tackling the opioid-overdose epidemic. N Engl J Med 370: 2063 2066 .

15. Blum K, Chen AL, Chen TJ, Braverman ER, Reinking J, et al. (2008) Activation instead of blocking mesolimbic dopaminergic reward circuitry is a preferred modality in the long term treatment of reward deficiency syndrome (RDS): A commentary. Theor Biol Med Model 5: 24

16. Blum K, Liu Y, Wang W, Wang Y, Zhang Y, et al. (2014) rsfMRI effects of KB220Z ${ }^{\mathrm{TM}}$ on neural pathways in reward circuitry of abstinent genotyped heroin addicts. Postgrad Med: 1-10.

17. Willuhn I, Burgeno LM, Groblewski PA, Phillips PE (2014) Excessive cocaine use results from decreased phasic dopamine signaling in the striatum. Nat Neurosci 17: 704-709.

18. Tomasi D, Wang GJ, Wang R, Caparelli EC, Logan J, et al. (2015) Overlapping patterns of brain activation to food and cocaine cues in cocaine abusers: association to striatal D2/D3 receptors. Hum Brain Mapp 36: 120-136.

19. Caprioli D, Calu D, Shaham Y (2014) Loss of phasic dopamine: a new addiction marker? Nat Neurosci 17: 644-646.

20. Vereczkei A, Demetrovics Z, Szekely A, Sarkozy P, Antal P, et al. (2013) Multivariate analysis of dopaminergic gene variants as risk factors of heroin dependence. PLoS One 8: e66592.

21. Gyollai A, Griffiths MD, Barta C, Vereczkei A, Urbán R, et al. (2014) The genetics of problem and pathological gambling: a systematic review. Curr Pharm Des 20: 3993-3999. 